Pedro de Figueiredo Saud

Dissertação apresentada como requisito parcial para obtenção do título de Mestre pelo Programa de PósGraduação em Economia da PUC-Rio.

Orientador: Ilan Goldfajn 
Pedro de Figueiredo Saud

\section{Estudando Flutuações da Potência da Política Monetária}

Dissertação apresentada como requisito parcial para obtenção do título de Mestre pelo Programa de PósGraduação em Economia da PUC-Rio. Aprovada pela Comissão Examinadora abaixo assinada.

Ilan Goldfajn

Orientador

PUC-Rio

Márcio Gomes Pinto Garcia

PUC-Rio

\section{Marcelo Kfoury Muinhos}

Citibank

João Pontes Nogueira

Coordenador Setorial do Centro de Ciências Sociais - PUC-Rio

Rio de Janeiro, 23 de março de 2007 
Todos os direitos reservados. É proibida a reprodução total ou parcial do trabalho sem autorização da universidade, do autor e do orientador.

\section{Pedro de Figueiredo Saud}

Graduou-se em Economia pelo Departamento de Economia da PUC-Rio em 2004. Foi bolsista por desempenho acadêmico durante a graduação e a pós-graduação. Concluiu o Mestrado de Economia em 2007.

Ficha Catalográfica

CDD: 330 


\section{Agradecimentos}

Ao meu professor e orientador, Ilan Goldfajn, pelo apoio e pelo exemplo fundamentais para o sucesso deste trabalho e para meu amadurecimento na profissão.

A Márcio Gomes Pinto Garcia e a Marcelo Kfoury Muinhos, componentes da banca, pela leitura cuidadosa e pelos importantes comentários ao trabalho.

A meus colegas do mestrado, pelo convívio e troca de idéias que tanto enriqueceram o mestrado, em especial Marcos Vivacqua e Diogo Almeida, e a meus outros amigos que tiveram papel fundamental ao longo desses anos, em especial Helena Veronese, Alice Salomão e Antônio Azevedo.

À CAPES, pelo apoio financeiro durante o mestrado.

A minha família. 


\section{Resumo}

Saud, Pedro. Estudando Flutuações da Potência da Política Monetária. Rio de Janeiro, 2007. 52p. Dissertação de Mestrado - Departamento de Economia, Pontifícia Universidade Católica do Rio de Janeiro.

A política monetária brasileira opera, desde 1999, sob o regime de metas para a inflação, em que a taxa de juros é o principal instrumento utilizado para o cumprimento das metas. Esta dissertação estuda o efeito da política monetária sobre o nível de atividade, e fatores que possam fazê-lo flutuar, através da estimação de uma curva IS para o Brasil. Inicialmente, encontramos efeitos significantes da taxa real de juros para o produto em uma curva IS backwardlooking. Em seguida, a partir de um modelo teórico, explicamos variações desse efeito como decorrente de ganhos de eficiência da atividade de intermediação financeira. Utilizando a tendência dos spreads bancários como medida da eficiência da atividade de provisão de crédito na economia, testamos empiricamente esta hipótese, e constatamos que o aumento da potência da política monetária observado ao longo dos últimos anos é consistente com essa explicação. Testes realizados com variáveis fiscais não encontram correlação entre estas e a potência da política monetária.

\section{Palavras-chave}

Política monetária; Canal do crédito; Curva IS 


\section{Abstract}

Saud, Pedro. Studying Fluctuations in the Potency of Monetary Policy. Rio de Janeiro, 2007. 52p. M.Sc. Dissertation - Departamento de Economia, Pontifícia Universidade Católica do Rio de Janeiro.

Monetary policy in Brazil has been working, since 1999, under an inflation targeting regime, in which interest rates are the main instruments in achieving the targets. This dissertation studies the effect of monetary policy on the economy's output and reasons for its fluctuations, through the estimation of an IS curve for Brazil. We find a significant effect of the real interest rate on output in a backward-looking IS curve. We then explain, using a theoretical model, variations in this effect as arising from efficiency gains in the financial intermediation activity. Using the trend over time of bank spreads as a measure of the efficiency of the lending activity, we test this hypothesis empirically, and find that the higher potency observed in the monetary policy on recent years is consistent with this explanation. Tests using fiscal variables do not find correlation between them and the potency of monetary policy.

\section{Keywords}

Monetary policy; Credit Channel; IS Curve 


\section{Sumário}

1 Introdução

2 Estimação de uma Curva de Demanda Agregada para o Brasil 13

2.1. Séries de Dados

2.2. Estimação do Modelo 16

$\begin{array}{ll}\text { 2.3. Teste de Robustez } & 21\end{array}$

3 Influência do Canal do Crédito Sobre o Efeito da Política Monetária Sobre o Produto 22

3.1. O Mercado de Crédito no Brasil na Última Década 25

3.2. Teste empírico 29

3.3. Dados utilizados 30

3.4. Resultado da Estimação 31

3.5. Interpretação 32

3.6. Testes de Robustez 33

4 Interação entre Políticas Fiscal e Monetária 37

4.1. Teste empírico 38

4.2. Séries de Dados 39

4.3. Resultados das Estimações $\quad 40$

4.4. Interpretação 41

4.5. Teste de Robustez 42

5 Considerações Finais $\quad 45$

6 Referências Bibliográficas $\quad 47$

7 Apêndice - Gráficos das Séries Utilizadas $\quad 49$ 


\section{Lista de figuras}

FIGURA 1: Evolução da Relação Crédito / PIB, 1996-2006 26

FIGURA 2: Evolução dos Spreads Bancários e da Taxa Selic, 1995-2006 27

FIGURA 3: Correlações do Spread Médio Residual com o Hiato do

$\begin{array}{ll}\text { Produto em } t+i & 28\end{array}$

FIGURA 4: Tendência do Spread Bancário Médio 30

FIGURA 5: Proxy para Eficiência do Mercado de Crédito e Dummy para Câmbio Fixo 36

FIGURA 6: Hiato do produto, 1996:1 - 2006:2 49

FIGURA 7: Juros Reais no Trimestre $\quad 50$

FIGURA 8: Variação Percentual da Renda Média Real 50

FIGURA 9: Medida de tendência dos spreads bancários utilizada como proxy para a eficiência da intermediação financeira na economia 50

FIGURA 10: Variação da Razão entre a Dívida Líquida do Setor Público e o PIB 51

FIGURA 11: Variação da Razão entre o Déficit Primário e PIB 51

FIGURA 12: Variação da Razão entre o Déficit Nominal e o PIB 51

FIGURA 13: Variação Real das Despesas Totais do Tesouro

Nacional com Relação ao Mesmo Mês do Ano Anterior 52

FIGURA 14: Variação das Despesas Totais do Tesouro Nacional com

Relação ao Trimestre Imediatamente Anterior 52

FIGURA 15: Variação das Despesas Totais do Tesouro Nacional com

Relação ao Trimestre Imediatamente Anterior, na Série Com Ajuste Sazonal 52 


\section{Lista de tabelas}

TABELA 1: Teste do Instrumento para a Expectativa de Hiato 18

TABELA 2: Estimação do Modelo Irrestrito 18

TABELA 3: Estimação do Modelo Backward-looking 19

TABELA 4: Intervalos de Confiança de 95\% Calculados por Bootstrap 21

TABELA 5: Intervalos de Confiança de 90\% Calculados por Bootstrap 21

TABELA 6: Estimação da Equação 4

TABELA 7: Resultado do Bootstrap ao Nível de Significância de 5\% 33

TABELA 8: Regressão com Medida de Eficiência como Controle na Equação 4

TABELA 9: Teste com Dummy entre 1996:1 e 1998:4 35

TABELA 11: Estimação da Equação 7

TABELA 12: Estimação da Equação 6 sem a Variável do Mercado de Crédito

TABELA 13: Estimação da Equação 7 sem a Variável do Mercado de Crédito 